\title{
Programas de transferência de renda em duas Unidades de Conservação na Amazônia brasileira e Sustentabilidade
}

\section{The impact of cash transfer programs in two protected areas in the brazilian amazon}

Deborah de Magalhães Lima - Doutora em Antropologia pela Universidade de Cambridge, Reino Unido. Professora do Programa de Antropologia da Universidade Federal de Minas Gerais (UFMG). E-mail: deb.m.lima@gmail.com

Nelissa Peralta - Doutora em Sociologia pela Universidade Federal de Minas Gerais. Pesquisadora Titular do Instituto de Desenvolvimento Sustentável Mamirauá (IDSM/ OS-MCTI). E-mail:nelissa@mamiraua.org.br.

\section{Resumo}

$\mathrm{O}$ artigo examina o impacto de benefícios na economia doméstica das duas primeiras RDS do Amazonas - Mamirauá e Amanã. Na amostra de 920 domicílios, em 2010, a renda média mensal foi de 1,5 salários mínimos e R $\$ 148,00$ per capita. A distribuição da renda se mostrou uniforme (Gini=0,075), com diferenciação econômica ligada ao ciclo de desenvolvimento doméstico - famílias abaixo da linha da pobreza são maiores e têm chefes mais jovens. A contribuição dos benefícios chega a $44 \%$ da renda e alcança $87 \%$ dos domicílios. A venda da produção - referência de campesinidade - contribui com $37 \%$ da renda total, mas em valores absolutos é maior entre os que recebem benefícios, sugerindo que criam condições favoráveis para a produção. Os benefícios ajudam a elevar o padrão de consumo em $30 \%$ e aumentam a compra de bens domésticos (70\%); significam maiores oportunidades de acesso à educação e saúde, por meio do usufruto de bens e serviços disponíveis nas cidades. Nas Reservas de Uso Sustentável os benefícios contribuem com o compromisso de melhoria das condições de vida. Apesar desse aporte, o padrão de renda se mantém baixo e $62 \%$ das famílias tiveram renda per capita abaixo do estabelecido como linha de pobreza.

\section{Palavras-chave}

Bolsa Família. Políticas de transferência de renda. Amazônia. Reservas de Uso Sustentável. Economia doméstica.

\begin{abstract}
The paper examines the impact of social benefits to household economy in the first Sustainable Development Reserves created in Amazonas, Mamirauá and Amanã. Our data from a sample of 920 households showed an average pattern of monthly household income of 1.5 minimum wages and per capita of $\mathrm{R} \$ 148$ in 2010 . The income distribution is remarkably uniform (Gini=0.075). The economic differentiation comes from the family development cycle - families with income below the poverty line are larger and their heads of household are younger. The contribution from government sources represents $44 \%$ of all income and reaches $87 \%$ of households. The sale of the production contributes on average to $37 \%$ of total income, but is higher among households receiving benefits, suggesting that by contributing to domestic stability, the benefits create more favorable conditions for production. Benefits help to raise the consumption levels by $30 \%$, increase the purchase of domestic assets goods (by $70 \%$ ) and ensure that regular purchase of consumer items; they also allow for greater opportunities for access to education, health and comfort, through the access of goods and services available in urban areas. In sustainable development reserves the benefits give an important support to help fulfill the commitment to improving the living conditions of the residents. Despite the positive impact of the benefits, income pattern remains low and $62 \%$ of families had per capita income below what has been established as the poverty line.
\end{abstract}

\section{Keywords}

Bolsa Familia. Cash transfer policies. Amazon. Sustainable Development Reserves. Household economics 


\section{INTRODUÇÃO}

No Brasil, a complexa relação entre pobreza e conservação da biodiversidade (cf. ADAMS; HUTTON, 2007) é enfrentada diretamente pelas Unidades de Conservação de Uso Sustentável. Criadas nos anos 1990, essas áreas protegidas resultaram de um pacto entre ambientalistas e movimentos organizados do campesinato amazônico. Com as reservas, as populações camponesas conquistaram garantias territoriais em troca de assumirem um compromisso com a conservação da biodiversidade. A partir daí, passaram a ser reconhecidas como Populações Tradicionais (SNUC, 2000; CARNEIRO DA CUNHA; ALMEIDA 2001).

As Unidades de Conservação de Uso Sustentável têm por objetivo conciliar conservação da biodiversidade e redução da pobreza por meio do desenvolvimento de projetos de manejo sustentáveis. Entretanto, a proposta de conjugar metas sociais e metas ambientais é ambígua e desafiadora, em grande parte porque as instituições que participam da gestão das reservas tendem a focar suas competências em uma dessas metas. No Amazonas, políticas públicas e instituições estaduais e federais participam da gestão de 58 Unidades de Conservação de Uso Sustentável, cobrindo uma área total de $248.178 \mathrm{~km}^{2}$ ou 15,8\% do território estadual (VERÍSSIMO et al., 2011). O maior esforço para a erradicação da pobreza é assumido pelos programas federais, principalmente o Bolsa Família. No Amazonas, os moradores das reservas são elegíveis a mais de cinco benefícios sociais, sendo dois condicionados e três previdenciários.

Nosso objetivo neste artigo é examinar o impacto desse conjunto de benefícios nas duas primeiras Reservas de Desenvolvimento Sustentável criadas no Amazonas, as RDS Mamirauá e Amanã. Discutimos o impacto dos programas de transferência de renda para a economia doméstica dos ribeirinhos, assim como o seu significado para o projeto político das Unidades de Conservação de Uso Sustentável. Esses resultados não são independentes, mas podem ser examinados em dois sentidos: o que os benefícios significam para famílias vivendo em uma Reserva? E o que os benefícios significam para os objetivos das Reservas?

Os dados consistem basicamente nos valores dos rendimentos e despesas domésticas. Embora a renda monetária seja considerada decisiva para a definição do bem-estar de uma população (ROCHA, 1997), para a população tradicional tratada neste estudo a importância da renda monetária não está relacionada tão somente à segurança alimentar, como nas áreas urbanas, mas se associa principalmente a oportunidades de acesso a bens de consumo e a serviços que lhes foram sempre muito restritos. 
Os seis tipos de benefícios que os moradores das RDS recebem têm garantias e condicionalidades diferentes. Os previdenciários (aposentadoria, pensão e salário maternidade) são assegurados por direitos constitucionais, enquanto que os benefícios condicionados são baseados em políticas públicas. O Programa Bolsa Família é uma política que beneficia famílias com renda per capita abaixo de $\mathrm{R} \$ 140,00$; suas condicionalidades estão relacionadas à frequência escolar e à saúde de crianças e adolescentes (CASTRO; MODESTO, 2010). Os outros dois benefícios condicionados - Bolsa Floresta e Seguro Defeso - estão ligados à participação em ações que promovem a conservação ambiental.

A Bolsa Floresta é um mecanismo para Redução das Emissões Derivadas de Desmatamento e Degradação (REDD+), destinado a recompensar financeiramente moradores de unidades de conservação do estado do Amazonas pelo seu papel na conservação das florestas (VIANA, 2008). A recompensa mensal de $\mathrm{R} \$ 50,00$ é repassada às mães de família, que assumem o compromisso de desmatamento zero em matas primárias. Já o Seguro Defeso tem abrangência federal. Foi concebido para compensar financeiramente os pescadores artesanais, pagando parcelas correspondentes a um salário mínimo durante os meses de interrupção de suas atividades no período reprodutivo das espécies.

O conjunto de benefícios incide sobre uma economia doméstica, que tem as características de um campesinato moderno: produz para vender e vende para comprar. A produção é autônoma e o grupo familiar é a unidade de referência para a produção e o consumo. Os rendimentos monetários dos ribeirinhos provêm da venda de produtos do trabalho (sobretudo da pesca e da agricultura), recebimento de salários, prestações de serviços e pequenos comércios. Essas fontes de renda foram acrescidas de benefícios previdenciários após 1990, e de benefícios condicionados 15 anos depois.

A transferência direta de renda pode alterar o volume da produção doméstica, influenciando tanto na sua redução quanto no aumento, dependendo de como se dá a relação entre trabalho e consumo doméstico. Como a produção dos ribeirinhos é destinada para custear o seu consumo, enquanto a demanda de consumo socialmente necessário for maior que a penosidade do trabalho ${ }^{1}$, o recebimento de benefícios não deve influenciar na redução da produção. Se, ao contrário, a produção aumentar, podemos concluir que a expectativa de consumo é maior do que o consumo propiciado pela renda acrescida dos benefícios.

\footnotetext{
Segundo Chayanov (1986), a produção camponesa é relacionada ao número de consumidores e produtores da unidade familiar. Os produtores avaliariam um aumento na produção em termos do benefício marginal em relação ao custo adicional ou penosidade do trabalho suplementar que teriam de despender. $\mathrm{O}$ aumento no padrão de consumo afeta essa avaliação.
} 
Os dados sobre consumo são, portanto, reveladores do padrão cultural das necessidades, que são variáveis no tempo e centrais para uma discussão sobre o impacto das políticas de transferência de renda.

A variação temporal no padrão de consumo em economias de orientação camponesa é tanto de longa escala - relacionada à expansão histórica do consumo de mercadorias e redução do autoabastecimento - quanto de escala familiar, associada ao ciclo de desenvolvimento do grupo doméstico. A influência das características demográficas sobre as práticas econômicas de camponeses (CHAYANOV, 1986; CHIBNICK, 1984) é relevante também para a nossa discussão sobre os benefícios sociais, sobretudo porque dois deles apresentam condicionantes relacionadas à dinâmica do grupo doméstico: as aposentadorias com as idades dos chefes; e o auxílio do programa Bolsa Família com a idade escolar dos filhos.

\section{MATERIAIS E MÉTODOS}

Os dados foram coletados em 2011, a partir de uma pesquisa recordatória realizada junto a uma amostra de 920 domicílios nas Reservas Mamirauá e Amanã. As casas estão distribuídas em uma área de 14.140 km², abrangendo oito municípios do Amazonas (Tonantins, Jutaí, Fonte Boa, Uarini, Alvarães, Coari, Maraã e Japurá), na região do Médio Solimões (Figura 1). A pesquisa registrou os itens mais frequentes do orçamento doméstico. As fontes de renda foram agrupadas nas categorias de venda da produção, salários, serviços e comércio, e o recebimento de benefícios. A despesa foi classificada em termos da sua destinação: para manutenção, compra de equipamentos e aquisição de bens domésticos. O ano de referência dos dados foi 2010, e a unidade de coleta foi o grupo doméstico: conjunto de moradores de um domicílio, invariavelmente ligados por laços familiares entre si e com membros de domicílios vizinhos.

O levantamento foi realizado em 205 das 270 localidades das duas reservas, cujo tamanho varia de 1 a 105 domicílios, com média de 13 casas. A amostragem aleatória cobriu 30\% dos domicílios de cada localidade, que representa 40\% dos 2.300 domicílios das duas reservas. 
Figura 1 - Área de estudo na região do Médio Solimões, Amazonas, Brasil.

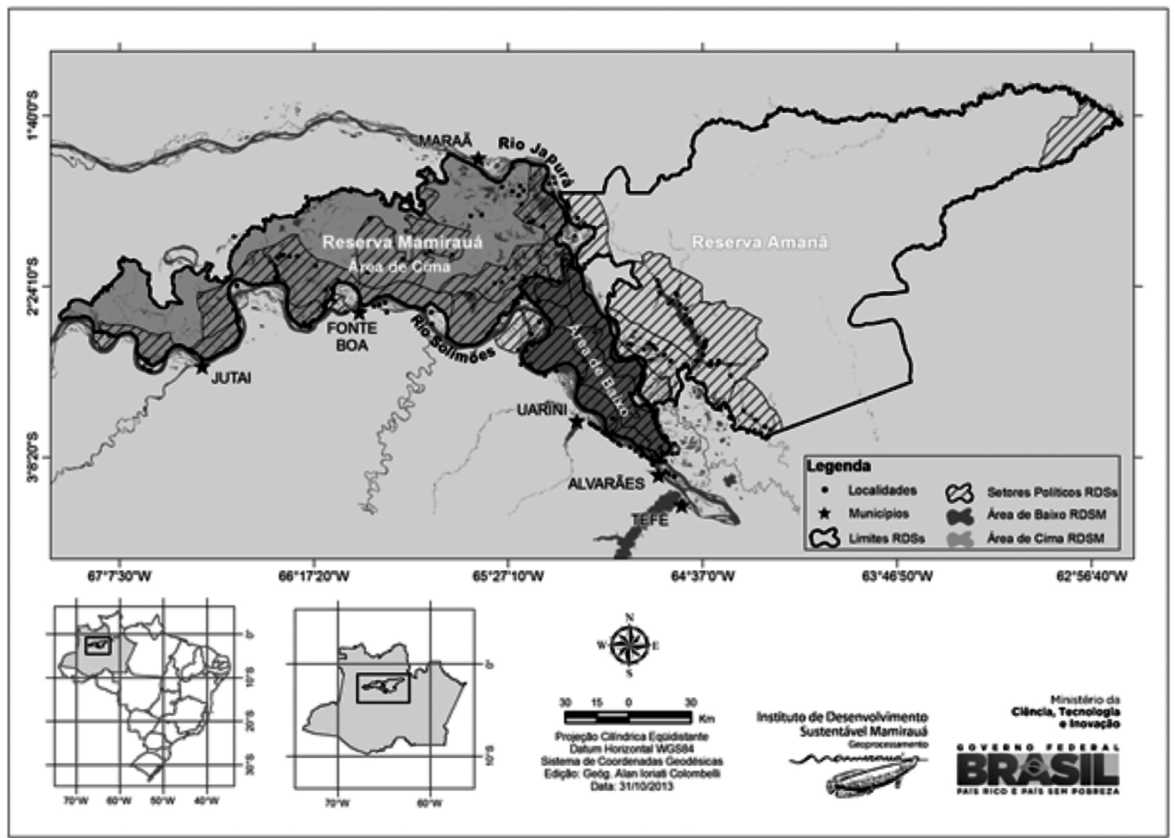

Fonte: Geoprocessamento IDSM, 2014.

\section{AS CONDIÇÕES DE VIDA}

A vida dos ribeirinhos é fortemente influenciada pelas condições ambientais. A Reserva Mamirauá localiza-se, na sua totalidade, em área de várzea, enquanto a Reserva Amanã é composta por florestas de várzea, terra firme e igapó. As florestas de várzea caracterizam-se por uma inundação anual que pode alcançar até 12 metros de profundidade, quando os rios e os canais de águas brancas circundantes transbordam, ocorrendo uma renovação de nutrientes que torna essas áreas muito produtivas. Os igapós são áreas de florestas que sofrem alagações sazonais devido à vasão dos rios de água preta. As florestas de terra firme não são inundáveis e apresentam maior diversidade de espécies, embora os solos sejam considerados menos produtivos (JUNK, 1997).

As principais atividades produtivas são a pesca e a agricultura, juntamente com a caça, o extrativismo e a extração de madeira, que são voltadas ao mercado e autoconsumo. Na várzea, a principal atividade direcionada ao mercado é a pesca, enquanto em áreas de terra firme é a agricultura. Nas florestas de terra firme, além da agricultura de corte e queima, há cultivos mais perenes nos sítios, roças e quintais. Já nas várzeas, a agricultura migratória é de ciclo rápido. 
O calendário da produção, o ritmo do consumo, a variação dos rendimentos e até a mobilidade das famílias são influenciados pelas dinâmicas ambientais, especialmente durante as grandes cheias ou secas. A variação sazonal no nível das águas afeta a disponibilidade de pescado, caça e terras para o cultivo e, por conseguinte, a produção. Quando as alterações ambientais extrapolam os níveis de variação regulares há uma queda na produção tanto das roças quanto da pesca.

A maioria dos grupos domésticos é formada por famílias relativamente grandes e jovens. Em 2010, a média de moradores por domicilio era 6,33 ( \pm 3 ) e a idade dos chefes de 44 anos ( \pm 15$)$. As condições locais de atendimento à saúde e à formação escolar ainda são precárias, refletindo a complexidade da pobreza rural na Região Norte (BUAINAIN et al., 2013). Nas duas reservas, apenas cinco das 270 localidades dispõem de postos de saúde em funcionamento. Para acessar serviços de atendimento à saúde, a população precisa se deslocar para as cidades mais próximas.

Os indicadores de educação também refletem a precariedade do ensino. Em 2011, 17\% da população com mais de 15 anos não sabia ler, uma fração praticamente duas vezes maior que a taxa de 8,6\% registrada pelo IBGE para o Brasil no mesmo ano ${ }^{2}$. Entre os chefes de família da Reserva Mamirauá $(\mathrm{n}=395)$, apenas $52 \%$ tinham cursado até a $4^{\text {a }}$ série do ensino fundamental. A maioria das localidades possui escolas municipais que atendem apenas do $1^{\circ}$ ao $5^{\circ}$ ano. Para seguir os estudos, as crianças e jovens precisam se deslocar para as cidades mais próximas.

Quanto ao saneamento, 64\% dos domicílios não dispõem de sistemas de tratamento de dejetos (GOMES et al., 2013). Apesar desse quadro, no período de 20 anos, entre 1991 e 2011 houve uma redução da taxa de mortalidade infantil na Reserva Mamirauá, que decresceu de 85 óbitos para cada grupo de mil crianças nascidas vivas em 1991 para 21 em 2011 (NASCIMENTO et al., in prep.), um valor similar ao do estado do Amazonas no mesmo ano (IBGE, 2011).

\section{A EVOLUÇÃO RECENTE DAS TROCAS MERCANTIS}

A economia doméstica dos ribeirinhos dinamiza-se por meio das trocas mercantis simples. Até a década de 1960, predominava o aviamento, um sistema de trocas baseado na dívida, em que um patrão-comerciante fornece mercadorias a crédito em troca da produção, principalmente extrativista (SANTOS 1980; ALMEIDA, 1993). A economia local era pouco monetizada e as famílias dependiam quase que exclusivamente da sua produção para obter mercadorias. Como em outras áreas onde o aviamento prevaleceu, as trocas eram calculadas

2 Fonte: http://seriesestatisticas.ibge.gov.br. 
monetariamente, mas não incluíam a circulação de dinheiro. A relação comercial envolvia um forte componente de dominação. O patrão controlava a realização das trocas de produtos e mercadorias, lucrando em ambas as operações e administrando a manutenção de uma dívida dos fregueses.

Com o declínio do aviamento, os ribeirinhos passaram a vender a produção com mais liberdade, negociando com pequenos comerciantes e patrões itinerantes, nos regatões (McGRATH, 1989) ou diretamente nas cidades. Estando libertos do jugo do patrão tradicional, puderam usufruir de melhores condições para o comércio, mas os baixos preços alcançados pelos seus produtos implicavam em uma remuneração muito aquém do trabalho despendido.

A concepção orçamentária da economia doméstica foi sendo alterada com o acesso direto aos recursos monetários. Começando com o recebimento de salários e aposentadorias rurais a partir dos anos 1990, seguidos dos benefícios condicionados e de compensação ambiental a partir de meados de 2000, a troca mercantil foi sendo gradativamente mediada pelo dinheiro, antes muito escasso devido ao predomínio do aviamento. Na região em estudo, os benefícios foram os principais responsáveis por um aumento significativo na circulação de dinheiro.

Nos últimos 20 anos, as fontes de rendimentos da economia ribeirinha diversificaram e houve também um aumento absoluto na renda da produção, em virtude da valorização comercial dos produtos. Um estudo longitudinal em quatro localidades da RDS Mamirauá acompanhou a evolução da contribuição da produção para a composição dos orçamentos domésticos ${ }^{3}$. Em um intervalo de 15 anos, a participação média da venda da produção caiu de 59\% para 18\%, em função da entrada de outros rendimentos, em especial dos benefícios. Porém, em valores absolutos, o ganho com a venda da produção aumentou 33\%, enquanto a renda mensal total, incluindo todas as fontes e refletindo o impacto dos benefícios, subiu em média 335\%.

\section{PERFIL ORÇAMENTÁRIO MÉDIO: PADRÃO DE RENDIMENTOS E DE GASTOS DOMÉSTICOS}

Em 2010, os 217 domicílios obtiveram uma renda anual média de $\mathrm{R} \$ 9.047,00$. Mensalmente, a renda familiar foi de 1,5 salários mínimos da época $(\mathrm{R} \$ 754,00)$ e $\mathrm{R} \$ 148,00$ em valores médios per capita (mediana $\mathrm{R} \$ 106,00$ ).

\footnotetext{
Em 1991, a renda familiar mensal média era de US\$40, basicamente da venda de produtos agrícolas. Em 1994/95, a venda do pescado aumentou (refletindo o impacto da criação da Reserva) e a renda familiar mensal alcançou US\$ 64. A evolução das trocas mercantis nessas comunidades difere do perfil das 205 comunidades deste estudo, exposta a seguir. Em 2010, a produção média das quatro comunidades foi US $\$ 85$, quase a metade do valor da amostra total, expressando a diversidade de padrões de rendimentos, associada a diferenças na localização geográfica e no acesso aos recursos, além das diferenças pessoais.
} 
O Figura 2 mostra a composição da renda mensal: 37\% provêm da venda da produção; $19 \%$ de salários, pequeno comércio e prestação de serviços; $22 \%$ de benefícios previdenciários e $22 \%$ de programas de transferência de renda condicionada. O total de benefícios representa $44 \%$ da renda, enquanto a contribuição do trabalho soma 56\%. A contribuição específica da venda da produção, em média $37 \%$ da renda total, pode ser vista como uma referência de "campesinidade" no contexto atual de pluriatividade econômica.

Figura 2 - Orçamento doméstico em 2010, composição da renda e da despesa média mensal $(\mathrm{n}=920)$.

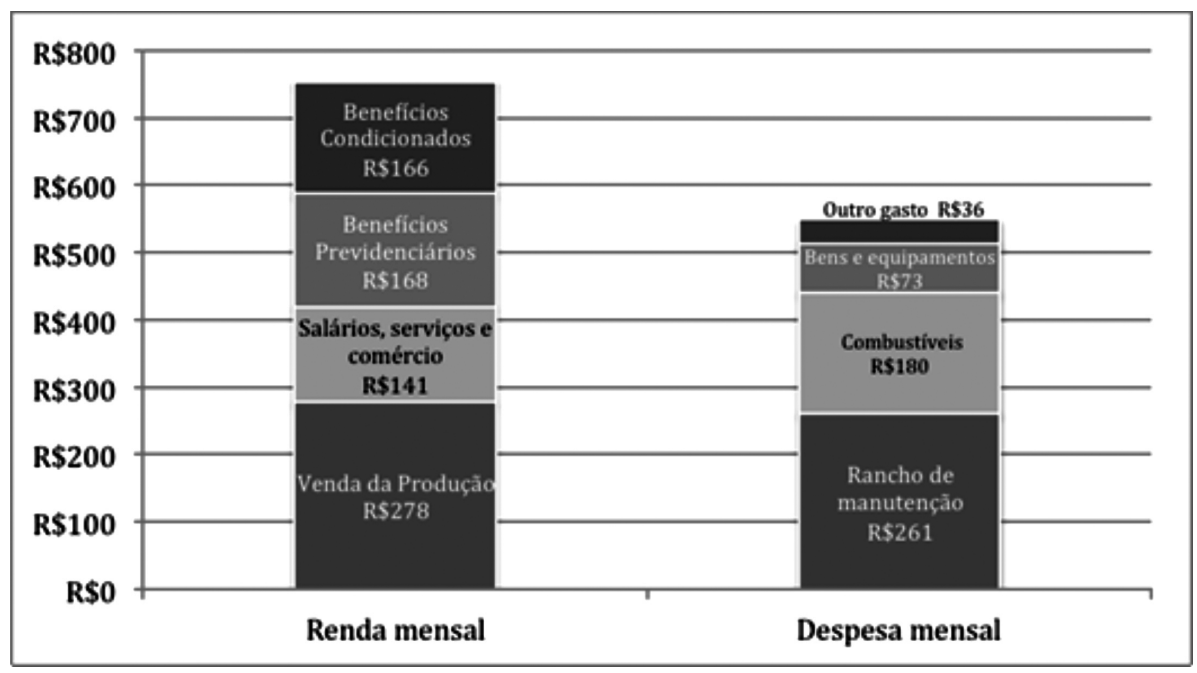

Fonte: Elaboração das autoras.

Dos 920 domicílios, 90\% venderam parte da produção, 21\% contaram com a participação de salários e 87\% receberam algum tipo de benefício.

Os principais produtos disponíveis para a venda provêm da pesca, agricultura, extração de madeira, artesanato, criação de animais e extrativismo. Dentre os domicílios, 69\% venderam pescado e 32\% venderam farinha.

Dentre os assalariados, 69\% são funcionários municipais, com funções de professores, merendeiras, agentes de saúde e condutores de embarcações, enquanto 31\% são contratados por outras organizações. A renda domiciliar mensal média dos que receberam salários foi $R \$ 1.060,00$, e a per capita $R \$ 187,00$. Isso significa, respectivamente, um ganho entre $\mathrm{R} \$ 306,00$ e $\mathrm{R} \$ 39,00$ a mais do que a média geral. Entre os assalariados, os ganhos com a venda da produção foram 18\% mais baixos em comparação aos domicílios que não recebem salários. A diferença está relacionada principalmente a menores rendimentos oriundos da 
pesca. Mesmo apresentando rendimentos mais altos, as famílias que receberam salários não deixaram de produzir para o mercado, apenas diminuíram o volume da produção.

Com a diversificação das fontes de rendimentos, o aporte dos programas de transferência de renda e a monetarização da economia rural, o padrão de consumo das famílias foi alterado. O maior poder aquisitivo ampliou o acesso aos bens de consumo e patrimoniais, e transformou radicalmente as condições de vida das famílias, em termos materiais.

O gasto doméstico médio em 2010 foi $\mathrm{R} \$$ 551,00 mensais e $\mathrm{R} \$ 107,00$ per capita. Para caracterizar a despesa doméstica, agrupamos os gastos em quatro categorias principais: rancho $^{4}$, combustíveis, bens de patrimônio doméstico e outros gastos (Figura 1). A despesa com o consumo doméstico de manutenção - rancho, botijão de gás e combustíveis usados no transporte fluvial - representou $80 \%$ dos gastos.

O rancho é a despesa mais alta. Mesmo sendo composto principalmente, por gêneros alimentícios, não abrange todo o consumo alimentar, pois a alimentação básica (peixe, farinha, frutas, legumes e temperos) é geralmente provida pela própria família. O segundo gasto mais alto e com o combustível. O peso desse investimento expressa o aumento da mobilidade, possibilitada pela aquisição de rabeta ${ }^{5}$ pela maioria das famílias.

O desempenho econômico das famílias pode ser avaliado interpretando a compra de bens de patrimônio doméstico como um saldo positivo. A noção de saldo permite inferir o balanço orçamentário e, dessa forma, balizar nossos dados de rendimentos, cuja origem é recordatória. Um saldo zero seria resultado dos rendimentos destinados apenas à manutenção da casa (que os ribeirinhos chamam "despesa com o rancho") e a aquisição de bens duráveis indicaria um resultado acima disso. Os ribeirinhos não falam mais em saldo quando discorrem sobre a sua economia doméstica. Mas essa foi a referência histórica para as trocas mercantis no aviamento, que envolvia uma contabilidade disputada e orientava o relacionamento comercial entre o patrão e o freguês. Além disso, o balanço entre ganhos e despesas é central para o estudo de qualquer economia doméstica ${ }^{6}$.

$\mathrm{Na}$ média geral, a compra de bens representou $11 \%$ das despesas (Gráfico 1). No entanto, apenas 51\% das famílias ultrapassaram os gastos simples

\footnotetext{
4 Denominação regional para o conjunto das despesas domésticas de alta reposição, gêneros alimentares e de limpeza. Os itens mais frequentes são açúcar, café, sabão, óleo e leite. Motor de popa usado em canoas - o principal meio de transporte regional.

Saldo evita induzir ao mesmo equívoco de excedente, como uma venda da produção se daria após o autoconsumo. Ao focar no destino da produção, a noção de excedente deixa de observar o consumo adquirido, que é, afinal, o objetivo da venda da produção camponesa.
} 
de manutenção e obtiveram esse saldo positivo. $\mathrm{O}$ valor médio anual da compra de bens foi $\mathrm{R} \$ 1.372,00$. Uma proporção menor de casas comprou equipamentos, $33 \%$, gastando, em média, $\mathrm{R} \$ 528,00$. A compra de bens ou equipamentos de trabalho foi efetuada por $66 \%$ dos domicílios. Portanto, para aproximadamente um terço das famílias, as trocas envolveram estritamente a obtenção de itens de consumo não duráveis; para dois terços foi possível adquirir um bem ou um equipamento; e a metade das famílias pôde obter saldo positivo e adquirir algum bem durável.

Até o declínio do aviamento, o patrimônio das casas era composto por poucos bens. Fogão, espingarda, máquina de costura e telhas de alumínio eram bens altamente desejados. Em 2010, os domicílios apresentavam uma maior quantidade e variedade de bens materiais. Na nova paisagem rural, raramente se vê uma casa com a cobertura de palha, e apenas as famílias que são consideradas muito desprovidas não possuem fogão. No entanto, em comparação com o padrão nacional médio, o patrimônio doméstico dos ribeirinhos ainda é composto por poucos bens obtidos com muito esforço: apenas metade das famílias conseguiu comprar um bem durável. Televisão e rabeta foram os itens mais adquiridos: 17\% e 13\% dos domicílios, respectivamente, adquiriram esses itens em 2010. A seguir, 9\% das famílias compraram fogão a gás. Dos equipamentos de trabalho, os apetrechos de pesca são os mais citados: 73\% dos domicílios compraram esses equipamentos, enquanto 15\% adquiriram equipamentos agrícolas.

A dispersão dos bens entre os domicílios acompanha a ordem de aquisição: motor rabeta e fogão são encontrados em $89 \%$ das casas e a TV em $71 \%$. Metade possui cama, e um quarto das famílias possui motor de luz, freezer ou geladeira. Celular e casa na cidade compõem o patrimônio de $18 \%$ das famílias. A motosserra é encontrada em 16\% das casas e $8 \%$ possuem máquina de lavar roupa.

Entre os itens do patrimônio, destacamos a presença da poupança que, mesmo com uma frequência baixa de $7 \%$, indica a inclusão de instituições financeiras nas estratégias econômicas adotadas pelas famílias. Esses domicílios apresentaram renda média per capita mensal $\mathrm{R} \$$ 86,00 acima da média geral. Entre estes, 100\% declararam ter comprado bens em 2010, mostrando uma associação entre poupança e aquisição de patrimônio.

Não estudamos as razões pelas quais os ribeirinhos poupam. A relação entre poupança e renda não é necessariamente positiva, e tanto a transitoriedade quanto a imprevisibilidade da renda podem ser razões para poupar (DOUGLAS; ISHERWOOD, 2004). O mais significativo para este estudo é verificar a inversão 
da sequência da troca mercantil: a passagem da compra a crédito do aviamento para a poupança e adiamento do consumo.

Como observado em outras regiões da Amazônia (PINEDO-VASQUEZ et al., 2008), cresce o interesse por uma segunda casa na cidade, para conciliar a vida urbana e a rural. A estratégia é buscada especialmente pelos moradores da várzea, pois possibilita um abrigo seguro na época da cheia. Para todos, é uma condição essencial para os filhos estudarem nas cidades. Embora apenas 18\% das famílias possuam uma segunda casa, é comum serem compartilhadas com os vizinhos.

Dadas as diferenças nas quantias, na regularidade e na origem de cada ingresso de recurso monetário, não seria surpresa observar a existência de destinações particulares para os gastos feitos com cada tipo de rendimento (cf. ZELIZER, 2011). Percebemos a destinação particular dada ao Seguro Defeso para a compra de instrumentos de pesca: das 214 famílias beneficiadas com o seguro, um terço comprou equipamentos de trabalho. Embora essa proporção seja semelhante entre aquelas que não recebem o seguro, o gasto médio com equipamentos foi significativamente maior entre as que receberam o seguro $(\mathrm{R} \$ 758,00)$ do que as que não receberam $(\mathrm{R} \$ 442,00)$. Em seu estudo, Mota et al. (2013) também verificaram o uso do auxílio defeso para a compra de equipamentos de pesca. Os autores contrastam esse uso com o Programa de Aquisição de Alimentos e o Bolsa Família, usados para despesas domésticas. O estudo de Eger e Damo (2014) também mostra o gasto preferencial do Bolsa Família nas despesas com a educação das crianças.

Destacamos a correlação $(\mathrm{p}<0,01)$ entre o valor médio do rancho ( $\mathrm{R} \$ 261,00)$ e a renda média da produção $(\mathrm{R} \$ 278,00)$. Entre todas as categorias de consumo examinadas, o gasto com o rancho foi o que menos variou. O gasto com combustíveis também mostrou uma variação relativamente baixa, sugerindo a existência de um padrão cultural para o consumo de mercadorias de alta reposição, vinculado ao rendimento obtido com a venda da produção.

A existência desse padrão de consumo de manutenção é corroborado por uma comparação entre os gastos dos domicílios com renda per capita abaixo e aqueles acima da linha da pobreza. Enquanto os gastos com rancho e combustíveis não variam muito nas duas situações (aumento no valor de 17 e 38 pontos percentuais, respectivamente), a compra de bens acompanha a diferença no valor dos rendimentos, e o aumento é de 141 pontos percentuais entre as famílias com renda per capita acima da linha da pobreza. 


\section{POBREZA E DESIGUALDADE}

O orçamento familiar médio per capita dos ribeirinhos caracteriza a sua situação econômica como vulnerável, apesar do aporte dos benefícios. A vulnerabilidade econômica é adotada como base da definição de pobreza, avaliada por meio de linhas de corte. No Brasil, a linha de pobreza está relacionada ao conceito de pobreza absoluta (ROCHA, 1997), calculada com base nos custos necessários para o atendimento das necessidades nutricionais de uma família.

Nas áreas urbanas, a renda pode ser um bom indicativo da situação de pobreza porque a alimentação é obtida basicamente pela compra. Mas, sem indicadores complementares - como escolaridade, longevidade, felicidade, segurança, justiça e saúde ambiental - a renda se mostra uma medida limitada, especialmente mas áreas rurais, onde a produção familiar supre parte do consumo. Nessas situações, medidas baseadas apenas na renda podem superestimar ou subestimar a dimensão da pobreza (SEN, 2010).

Com essas observações, queremos fazer uma ressalva ao uso de medidas de pobreza baseadas apenas em rendimentos, inserindo uma nota de cautela à interpretação dos nossos próprios dados. Uma avaliação da pobreza relativa exigiria estudos qualificados que extrapolam os objetivos deste artigo. ${ }^{7}$

Rigorosamente, nossas estimativas medem a participação dos ribeirinhos na economia de mercado. A renda familiar só poderá ser um indicador proxy de pobreza quando a mercantilização da economia doméstica for mais abrangente e incluir significativamente, o consumo doméstico. Ou, como expressou um agricultor, ao criticar a mudança de hábitos alimentares na sua comunidade, quando a alimentação depender principalmente "do comprado"s.

É nesse sentido que os ribeirinhos vivem o paradoxo de só poderem ser efetivamente incluídos nas estimativas oficiais de pobreza quando os seus rendimentos monetários aumentarem e o seu autoconsumo diminuir. Ou seja, à medida que a sua integração ao mercado crescer, a comparação entre os seus rendimentos monetários e as linhas de corte de pobreza ganhará validade.

Mesmo reconhecendo a ironia dessa situação, confrontamos as nossas estimativas de renda com os principais indicadores de pobreza, pois são referências para a concessão de benefícios. O governo federal utiliza um Cadastro Único

\footnotetext{
Considerando o critério europeu para estimar pobreza relativa, $81 \%$ dos domicílios estudados tiveram renda média per capita familiar menor do que $60 \%$ da mediana nacional em 2010 (IBGE, 2011).

8 Entre os domicílios, $65 \%$ produzem a farinha para consumo próprio. A farinha é o alimento básico presente em quase todas as refeições das famílias locais. Sobre as mudanças na alimentação dos ribeirinhos, ver Piperata (2007).
} 
baseado no salário mínimo e classifica as famílias como sendo de baixa renda se obtiverem renda mensal de até meio salário mínimo per capita ou renda mensal total de até três salários mínimos.

De acordo com esse quadro, 39\% dos domicílios da nossa amostra obtiveram rendimento mensal total menor que o salário mínimo da época; $36 \%$ estavam entre um e dois salários mínimos; $17 \%$ entre dois e três salários mínimos, e apenas $8 \%$ apresentaram rendimentos acima de três salários mínimos. Em valores per capita, 58\% dos domićlios estavam abaixo de $1 / 4$ do salário mínimo e 85\% abaixo de meio salário mínimo.

As linhas de corte adotadas no Brasil definem como pobres as famílias cuja renda per capita é menor que $\mathrm{R} \$ 140,00$; e as abaixo de $\mathrm{R} \$ 70,00$ são consideradas em situação de extrema pobreza. Por esse parâmetro, 31\% das famílias da amostra estão em situação de extrema pobreza e 62\% estão abaixo da linha de pobreza. Por essa definição, a proporção de pobres na população estudada é maior do que no total nacional. É também maior do que a estimativa da pobreza rural brasileira como um todo (Figura 3).

Figura 3 - Proporção de pessoas por classes selecionadas de rendimento domiciliar per capita: totais nacionais e região de estudo (2010).

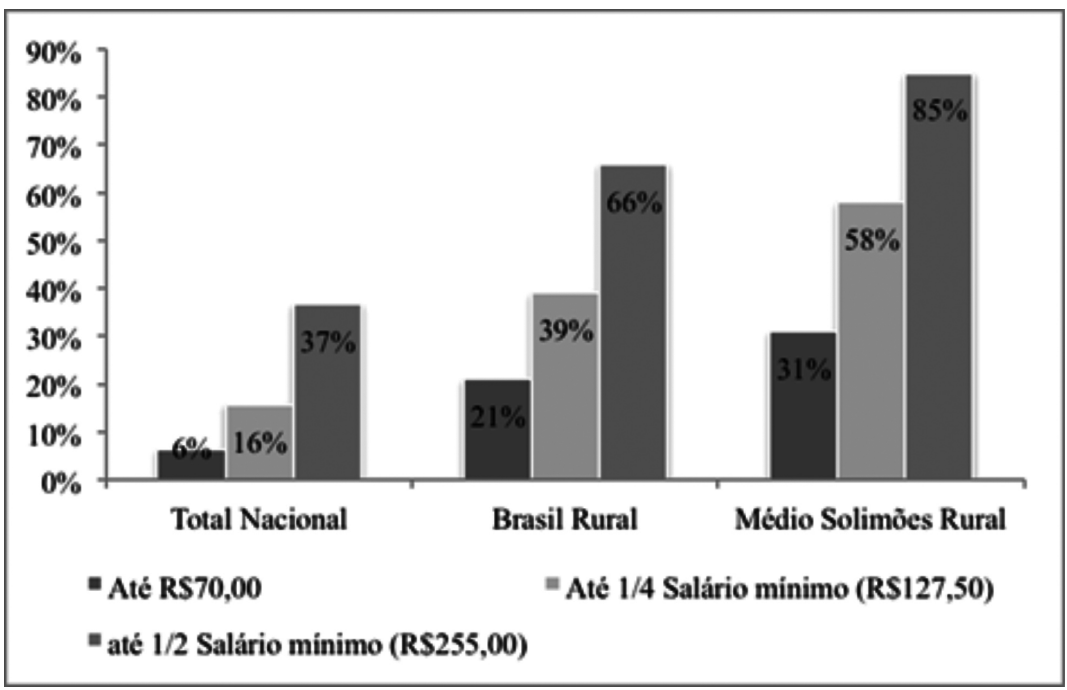

Fontes: IBGE (2011) e dados da pesquisa.

Por fim, aplicando um referencial internacional adotado pelas Nações Unidas para monitorar os Objetivos de Desenvolvimento do Milênio, 28\% dos domicílios tiveram renda per capita menor que US\$1,25 por dia, e 50\% dos domicílios apresentaram renda per capita menor que US $\$ 2,00$ por dia (PPP). 
No entanto, é importante notar que a amostra apresenta uma distribuição da renda per capita familiar notadamente uniforme, com um grau de concentração de renda expresso pelo coeficiente de Gini, de apenas 0,075. No Brasil, o índice de Gini medido pelo IBGE em 2010 foi 0,536; no estado do Amazonas, 0,531 na área urbana e 0,450 na área rural (IBGE, 2011). A baixíssima concentração de renda reflete a igualdade de condições de vulnerabilidade na população estudada.

\section{A BASE DEMOGRÁFICA DA DIFERENCIAÇÃO ECONÔMICA}

Não obstante a essa uniformidade, a análise da distribuição dos domicílios segundo a renda per capita familiar mostra a presença de um padrão demográfico, sugerindo uma associação entre a diferenciação econômica e as fases do desenvolvimento dos grupos domésticos. Os domicílios nas faixas de renda abaixo da linha da extrema pobreza (31\%) apresentam perfil demográfico de chefes mais jovens, em torno de 39 anos, e famílias maiores, compostas por oito membros. Os 38\% dos domicílios acima da linha de pobreza têm perfil de chefes mais velhos, em torno de 52 anos, e famílias menores, em torno de quatro membros. Observamos a correlação significativa entre as faixas etárias e a renda média per capita domiciliar, mais acentuada com relação à idade do chefe $(0,313 ; \mathrm{p}<0,01)$ do que com o número de pessoas por domicílio $(0,109 ; \mathrm{p}<0,01)$. A maior influência da idade do chefe sobre os rendimentos se deve às aposentadorias. A idade do chefe também indica o estágio do ciclo de vida doméstico no qual a família se encontra: famílias maiores têm maior oportunidade de expandir a produção para além das necessidades básicas de consumo. Como reflexo dessas condicionantes, as famílias cujo chefe está em idade de aposentadoria rural apresentam renda média 101\% maior do que aquelas com chefes mais jovens ( $<25$ anos).

As condicionalidades de dois benefícios estão direta ou indiretamente vinculadas às faixas etárias dos chefes - a aposentadoria, diretamente com a idade dos chefes; e o Bolsa Família, condicionado à frequência escolar dos filhos e indiretamente com a idade. Os dois benefícios se sobrepõem a um possível efeito chayanoviano de diferenciação socioeconômica que as famílias podem apresentar, ligado a variações demográficas na composição do grupo doméstico (CHAYANOV, 1986; CHIBNICK, 1984). Para avaliar a influência de fatores demográficos no volume de venda da produção, dividimos a amostra segundo a faixa etária do chefe de família (Tabela 1). 


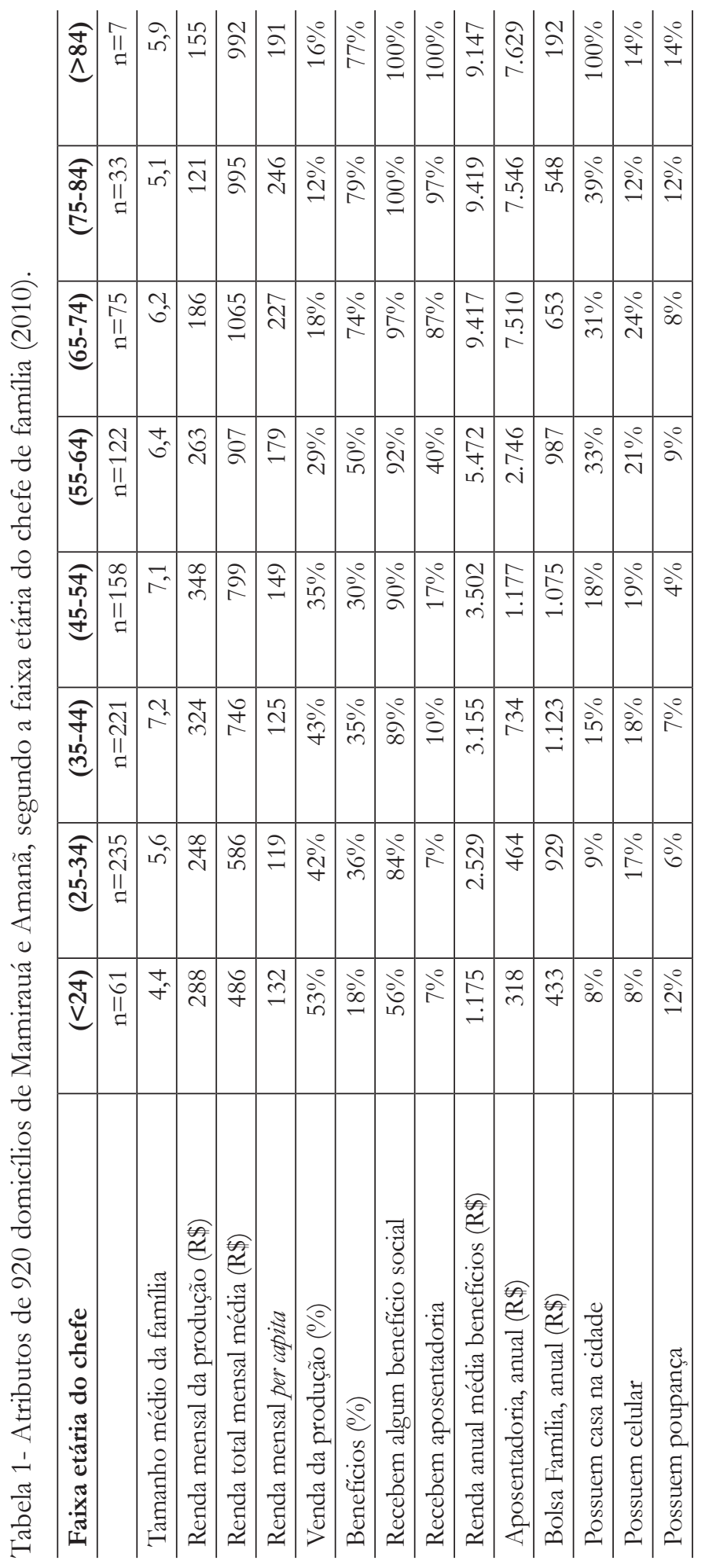


As famílias novas mostram um esforço de produção elevado, seguido de leve queda, correspondente à fase de crescimento da família; segue um crescimento da produção até alcançar o valor mais elevado, antes de 55 anos, quando cai rapidamente até atingir em torno da metade do valor inicial (Tabela 1). Os domicílios mostram um crescimento relativamente rápido, seguido de uma fase de dispersão demorada, conforme o chefe da família envelhece; entretanto, mesmo com idades mais avançadas, mantêm uma média de cinco moradores, aproximadamente. $\mathrm{O}$ recebimento de benefícios cresce de modo gradativo, de acordo com a idade do chefe, influenciado principalmente pela aposentadoria.

A renda mensal média domiciliar é maior nas faixas etárias mais idosas. A complementariedade entre renda da produção e da previdência e, de modo menos expressivo, os benefícios condicionados, mostra a importância dessas fontes de renda para os mais velhos. A partir dos 55-60 anos, observamos a queda na produção e o aumento da renda, proporcionado pela aposentadoria - o benefício mais significativo nas localidades pesquisadas.

Os domicílios que contam com aposentados dispõem de renda familiar $43 \%$ mais alta que os demais. Já o valor total da venda da produção se mostra $38 \%$ menor (de $\mathrm{R} \$ 3.672,00$ cai para $\mathrm{R} \$ 2.295,00$ ). O efeito da aposentadoria sobre a venda de produção agrícola é o mais acentuado - de R $\$ 1.3448$ anuais entre os sem aposentadoria, cai para $\mathrm{R} \$ 612,00$ entre os aposentados. A agricultura é a atividade que os ribeirinhos consideram mais trabalhosa, e cujo retorno financeiro é mais baixo. Os gastos com o rancho são muito parecidos, reiterando a existência de um padrão geral de consumo para manutenção. A maior diferença entre as famílias com e sem aposentadoria é a aquisição de uma casa na cidade $15 \%$ a mais entre os aposentados.

Sem a aposentadoria, os idosos, com capacidade produtiva reduzida, teriam que se manter basicamente com a venda da produção. A queda na venda da produção nessa faixa etária não se deve apenas ao recebimento de aposentadoria, pois, devido à idade avançada, os chefes de família já não têm o mesmo vigor para o trabalho. De todo modo, mesmo nas faixas etárias mais jovens, somente a produção não garante uma renda razoável, próxima dos valores oficialmente reconhecidos como provedores de segurança social. A principal razão são os preços e as limitações da produção, que depende da mão de obra familiar.

Em síntese, o perfil dos domicílios por faixa etária (Tabela 1) mostra que as famílias mais jovens são as mais vulneráveis. A renda familiar per capita só ultrapassa a linha oficial da pobreza a partir de 45 anos. Entre os chefes de meia idade, notadamente os aposentados, a renda familiar mensal atinge o valor de um salário mínimo e meio, mas depois ultrapassa esse patamar. Enquanto a 
contribuição da venda da produção cai nas faixas etárias mais altas, aumenta a importância relativa e absoluta dos benefícios, sobretudo o previdenciário. Esse resultado corrobora o padrão geral encontrado por Buainain et al. (2013), ao perguntarem "quem são os pobres no Brasil rural". Os autores mostram que os domicílios rurais mais pobres estão nas fases iniciais do ciclo de vida, ao passo que os menos pobres estão nas fases mais avançadas, que contam com o aporte das aposentadorias.

\section{ALCANCE E EFEITOS DOS BENEFÍCIOS}

Para a população deste estudo, a contribuição das fontes de rendimentos provenientes de benefícios e de programas governamentais chega a $44 \%$ da renda. A dimensão dessa cobertura assinala a importância dos benefícios sociais para a economia doméstica na região, sem os quais os rendimentos das famílias estariam ainda mais distantes da média nacional. A alta participação dos benefícios na composição da renda média tem relação também com os preços dos produtos regionais, desfavoráveis para os ribeirinhos. A renda média mensal obtida com a venda da produção doméstica em 2010 (R\$ 278,00) equivalia à venda de aproximadamente $200 \mathrm{~kg}$ de farinha ou de $40 \mathrm{~kg}$ de tambaqui.

O alcance dos programas de transferência de renda na economia doméstica em ambas as reservas é expressivo: 87\% dos grupos familiares receberam algum tipo de benefício (Tabela 2).

Tabela 2 - Incidência dos benefícios de transferência direta de renda ( $\mathrm{n}=920$ domicílios, 2010).

\begin{tabular}{llcr}
\hline \multicolumn{2}{c}{ Tipo de Benefício } & Cobertura & Valor médio anual R\$ \\
\hline \multirow{3}{*}{ Condicionados } & Bolsa Floresta & $67 \%$ & $\mathrm{R} \$ 696,00$ \\
\cline { 2 - 4 } & Bolsa Família & $62 \%$ & $\mathrm{R} \$ 1.511,00$ \\
\cline { 2 - 4 } & Seguro Defeso & $23 \%$ & $\mathrm{R} \$ 2.566,00$ \\
\hline \multirow{3}{*}{ Previdenciários } & Aposentadoria & $24 \%$ & $\mathrm{R} \$ 7.594,00$ \\
\cline { 2 - 4 } & Salário Maternidade & $4 \%$ & $\mathrm{R} \$ 2.014,00$ \\
\cline { 2 - 4 } & Pensão & $2 \%$ & $\mathrm{R} \$ 5.061,00$ \\
\hline
\end{tabular}

Os benefícios recebidos pelos residentes nos domicílios considerados neste estudo somaram $\mathrm{R} \$ 3.689 .892,00$, representando $\mathrm{R} \$ 634,00$ por pessoa/ ano (US\$358,00). A renda total gerada pelo trabalho foi $\mathrm{R} \$ 4.633 .258,00$; desses rendimentos, 66\% são oriundos da produção, 30\% dos salários e serviços e 4\% do comércio. A participação de ganhos do trabalho em relação àqueles com benefícios foi $26 \%$ maior. 
Os ribeirinhos tratam os benefícios como ganhos suplementares aos rendimentos da produção. Mesmo a aposentadoria, que deveria cobrir integralmente as despesas do assegurado, não garante uma renda suficiente para a maioria dos domicílios, que continua engajada em atividades produtivas voltadas ao mercado. Apenas 7\% dos domicílios vivem exclusivamente de benefícios, com renda média mensal de $\mathrm{R} \$ 552,00$, aproximada ao valor do salário mínimo à época. Entre todos os domicílios, apenas 3\% vivem apenas com recursos da aposentadoria, o benefício mais elevado ${ }^{9}$. Isso mostra dependência continuada da venda da produção, apesar do alcance e do volume dos benefícios dos programas governamentais.

Comparamos a renda per capita mensal média de domicílios em quatro situações: (i) que não recebem nenhum tipo de benefício ( $n=119 ; \mathrm{R} \$ 92,00$ ), vivendo em uma situação comparável à vigente em 1991; (ii) que recebem benefícios previdenciários, mas não benefícios condicionados, embora sejam elegíveis, por estarem abaixo da linha da pobreza ( $n=118$; $\mathrm{R} \$ 58,00$ ); (iii) que não contam com benefícios condicionados, mas com previdenciários, independente da faixa de renda média per capita ( $\mathrm{n}=168$; $\mathrm{R} \$ 127,00)$; e (iv) domicílios que recebem todos os benefícios, previdenciários e condicionados ( $\mathrm{n}=752 ; \mathrm{R} \$ 153,00)$.

Para explorar o efeito dos benefícios condicionados no orçamento domiciliar, comparamos os rendimentos dos domicílios com $(\mathrm{n}=752)$ e sem esses benefícios $(n=118)$, mas elegíveis. Os domicílios sem benefícios apresentaram renda média anual 60\% menor. Entre as famílias que recebem esses benefícios, a produção representou $35 \%$ da renda total; entre as que não recebem, a produção representou 63\%. Porém, em valores absolutos, a diferença é inversa, pois as famílias que contam com esses benefícios registraram uma venda da produção $30 \%$ maior $^{10}$ (Gráfico 3).

Dos três benefícios condicionados, o Bolsa Família (BF) é o mais controverso. Segundo uma concepção bastante disseminada, este auxílio teria gerado um "efeito preguiça" nos ribeirinhos, que agora trabalhariam menos. A análise do seu efeito específico sobre os rendimentos é dificultada pelo fato de raramente ser a única fonte de renda, visto que apenas $9 \%$ dos domicílios receberam somente o BF. Mesmo que seja impossível considerar o efeito do $\mathrm{BF}$ isoladamente, este auxílio, junto com outros benefícios, não provoca a acomodação das famílias, que mantêm uma produção para o mercado até mais elevada do que as famílias que não recebem o benefício (Figura 4).

\footnotetext{
Cujo valor médio em dólares era aproximadamente US\$360 mensais.

10 Teste t-Student mostrou diferença significativa $(\mathrm{p}<0,01)$ na comparação entre a venda da produção nas duas subamostras ( $\mathrm{n}=118$ e $\mathrm{n}=752)$.
} 
Figura 4 - Comparação entre a composição dos rendimentos e dos gastos anuais médios em domicílios com e sem benefícios condicionados, mas elegíveis (Mamirauá e Amanã, 2010).

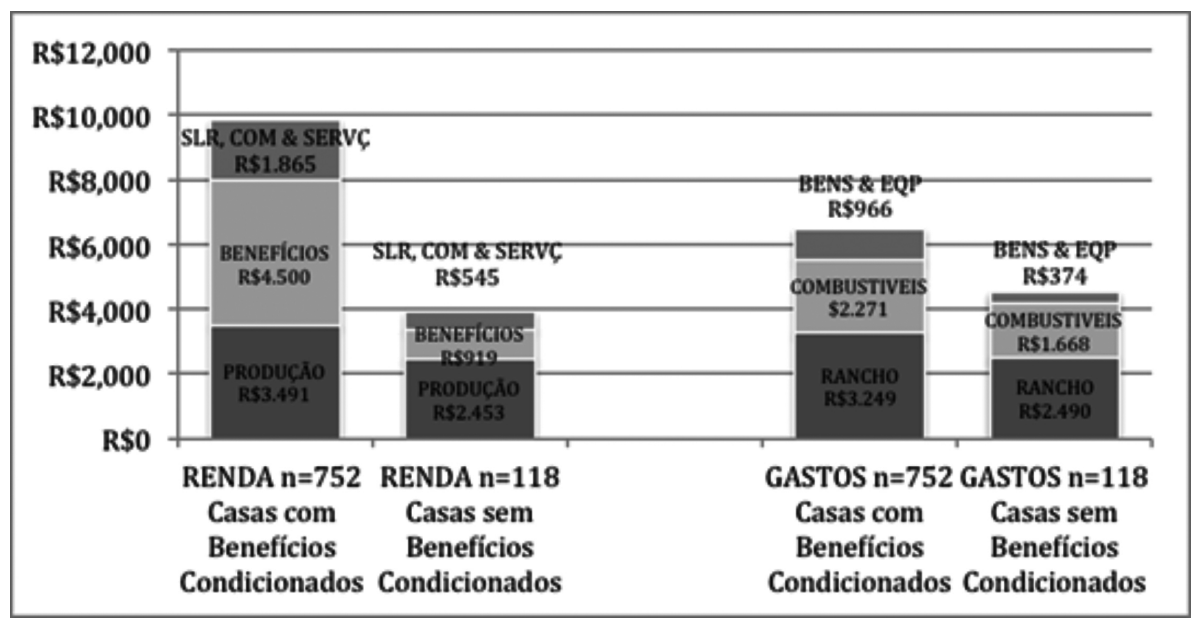

Esse resultado corrobora a interpretação do efeito dos benefícios previdenciários sobre a produção doméstica - de serem tratados como um complemento à venda da produção para cobrir as despesas domésticas. Os rendimentos oriundos da produção decaem nas faixas etárias mais altas, quando os chefes de família passam ter direito ao recebimento da aposentadoria rural, mas não desaparecem, e continuam contribuindo para a formação da renda familiar.

Há de se considerar, também, pelo menos duas dinâmicas sociais responsáveis pela motivação de trabalho e manutenção das atividades de produção para a venda: o trabalho cotidiano - os valores associados à honra dos chefes de família, que gira em torno da produção -, e a mudança rápida no padrão de consumo socialmente necessário, mesmo que seja simples, conduz a uma participação contínua nas trocas de mercado. A maior mobilidade entre a Reserva e a cidade, e a integração à vida urbana, também geraram gastos adicionais.

O efeito do conjunto de benefícios condicionados sobre a despesa doméstica é ilustrado pelo Gráfico 3. Há uma diferença em torno de 30\% em todos os gastos das famílias que recebem benefícios condicionados, exceto na compra de bens, que foi $70 \%$ mais alta, indicando uma economia mais expressiva, gerando um saldo positivo no orçamento doméstico. A proporção de domicílios que compraram bens também difere significativamente: 55\% entre os que recebem benefícios e $26 \%$ entre os que não recebem. 
O Figura 5 apresenta a contribuição média das diferentes fontes de renda e a variação na composição do orçamento doméstico, segundo a idade do chefe. A complementaridade entre as duas principais fontes de renda - produção e benefícios - denota um espectro de cobertura variável. Produção e benefícios condicionados predominam nas faixas etárias mais jovens, e produção e previdência nas faixas etárias mais idosas. Embora os benefícios condicionados apresentem uma distribuição relativamente uniforme entre 25 e 60 anos, são mais importantes para as famílias mais jovens. $\mathrm{Na}$ idade avançada, por outro lado, a aposentadoria praticamente dobra a renda familiar.

Os benefícios têm impactos distintos no orçamento doméstico, de acordo com a fase do ciclo de vida. A importância para a geração da renda e para a provisão do consumo varia de acordo com a idade do chefe, estabelecendo padrões orçamentários característicos para cada fase.

Figura 5 - Composição da renda familiar mensal por faixa etária do chefe de familia $(n=920)$.

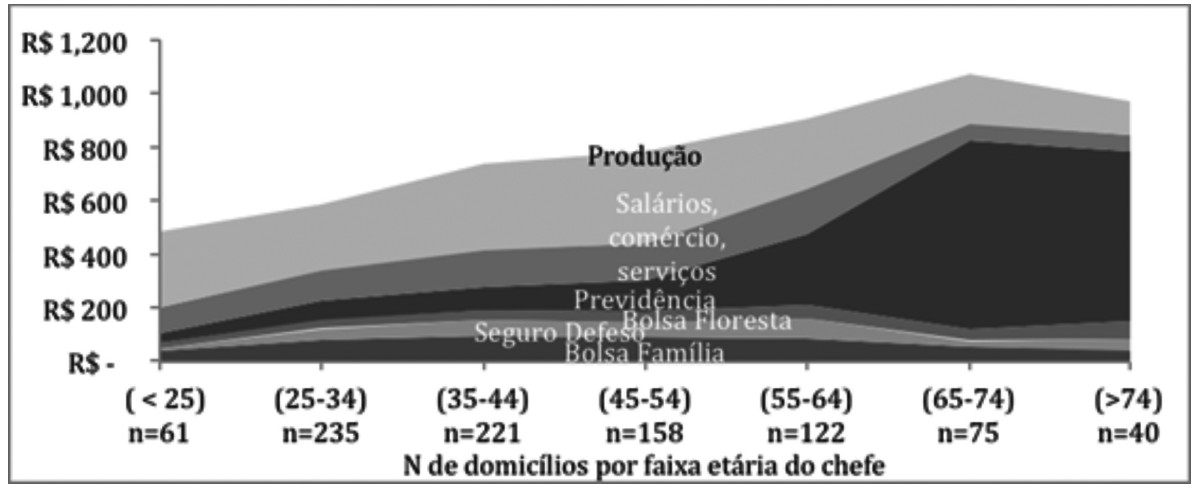

Por fim, examinamos o efeito geral dos benefícios condicionados sobre a distribuição da renda per capita, para indagar em que medida contribui para que população saia da pobreza extrema. Comparamos a proporção de famílias com e sem benefícios condicionados, em quatro faixas de renda per capita: até $\mathrm{R} \$ 35,00$; até $\mathrm{R} \$ 70,00$, até $\mathrm{R} \$ 140,00$ e acima linha da pobreza (Figura 6). Entre os que recebem benefícios condicionados, a proporção nas duas faixas de renda per capita de extrema pobreza é menor em 15 e 17\%. O impacto desses benefícios não é tão significativo no grupo III, em que a diferença é de $9 \%$. Já a diferença na proporção de famílias acima da linha da pobreza é inversamente proporcional, sendo $9 \%$ maior no grupo que recebe benefícios condicionados. Portanto, os benefícios condicionados mostram um efeito positivo para as famílias mais carentes que, como vimos, são majoritariamente as mais jovens e com filhos pequenos. 
Figura 6 - Proporção de domicílios por faixa de renda per capita, segundo o recebimento ou não de benefícios condicionados $(n=920)$.

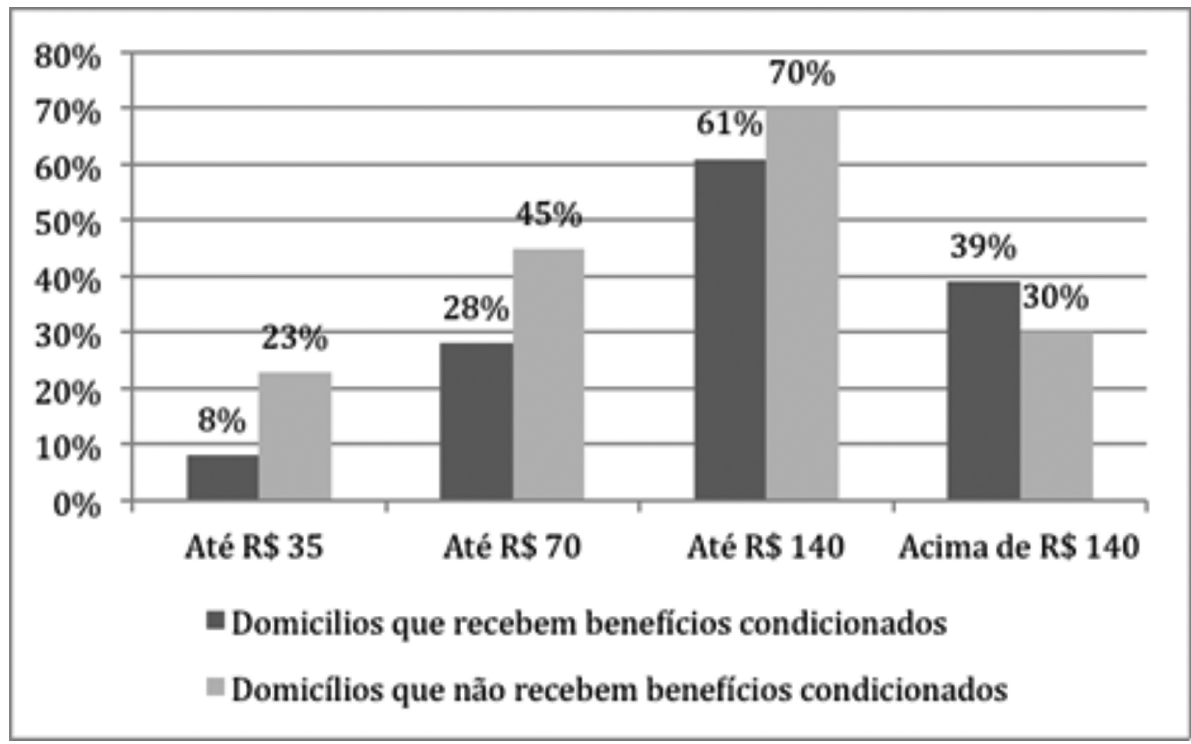

\section{DISCUSSÃO E CONCLUSÕES}

A contribuição do conjunto de programas sociais para a erradicação da pobreza nas duas reservas é inequívoca. O aporte financeiro propiciado pelos benefícios possibilita a aquisição de bens patrimônios e assegura a compra regular dos itens de consumo. Também possibilita maiores oportunidades de acesso à educação, saúde e conforto, por meio do usufruto de bens e serviços disponíveis nas áreas urbanas.

Os benefícios representam, em média, 44\% da renda total dos moradores, variando de $18 \%$ a $79 \%$, de acordo com a faixa etária do chefe da família. O alcance dos benefícios é amplo, e o que tem maior impacto sobre a renda é a aposentadoria. Embora o seu alcance seja restrito a $24 \%$ das famílias, a sua contribuição quase dobra o rendimento domiciliar. A renda monetária oriunda de benefícios condicionados é mais modesta, mas cumpre um papel importante entre as famílias mais jovens, diminuindo a vulnerabilidade econômica associada a essa fase do ciclo de vida do grupo doméstico.

O fato de as famílias que recebem benefícios condicionados obterem rendimentos de produção mais altos do que as que não recebem sugere que, ao contribuírem para a estabilidade doméstica, os benefícios criam condições favoráveis para produção. E, notadamente, não produzem o efeito oposto, de acomodação dos beneficiários. 
O efeito positivo dos benefícios sobre a produção econômica aponta também para a situação particular dos ribeirinhos nas Reservas de Mamirauá e Amanã: sua produção é dependente do ecossistema, subordinada à oferta de recursos naturais. Nas Reservas, os ribeirinhos usufruem de melhores condições de produção, sobretudo a pesqueira. A exploração dos recursos segue protocolos de manejo sustentável, que concedem aos moradores a prioridade de exploração ${ }^{11}$. Assim, os benefícios se somam às condições mais favoráveis encontradas em ambas as reservas, que se reflete na melhoria dos rendimentos oriundos da produção.

Por sua vez, os benefícios representam um importante suporte para a gestão das Reservas, reafirmando o compromisso com a melhoria das condições de vida dos moradores. A contribuição mútua das políticas sociais e ambientais deve ser ressaltada, para que as instituições reconheçam a imbricação de suas ações. A multideterminação e multicausalidade dos fenômenos em questão pobreza e sustentabilidade - impõem que a sua discussão seja feita em diversas escalas (BRONDÍZIO et al., 2009). A difícil equação entre pobreza e conservação ambiental inclui a definição das responsabilidades sociais. Quem deve assumi-las? As Unidades de Conservação não devem se abster de assumir um compromisso mais claro com a superação das carências sociais, nem deixar de participar ativamente das políticas sociais empreendidas em outras escalas institucionais.

Para estimar o impacto das políticas de transferência de renda, podemos imaginar um cenário contrafactual anterior (ver Gráfico 4). Sem esses benefícios, os rendimentos médios seriam dados basicamente pela renda da produção, com valor provavelmente menor. Em um cenário anterior às reservas, o rendimento da produção seria ainda mais baixo, pois não contaria com o aumento na produtividade da pesca e melhores condições de comercialização.

Para os moradores das reservas, o cancelamento dos benefícios seria trágico, pois mesmo com o impacto positivo dessas contribuições, a população continua nominalmente pobre: $85 \%$ famílias apresentaram renda per capita abaixo de meio salário mínimo, e $62 \%$ obtiveram renda per capita abaixo da linha da pobreza. A vulnerabilidade da população é dada não somente pelos indicadores de renda, mas decorre também da precariedade dos serviços públicos - educação, saneamento e saúde - oferecidos na área rural.

Por fim, advertimos sobre o recorte deste trabalho. Não discutimos o que é pobreza para os ribeirinhos, nem qual seria a sua avaliação dos impactos

11 Para conhecer esses programas de manejo e seus efeitos sobre as condições de vida, ver as publicações do Instituto Mamirauá. Disponíveis em: <http://www.mamiraua.org.br/pt-br/ publicacoes> 
das políticas de transferência de renda. Sabemos, no entanto, que, ao incidirem diretamente na economia doméstica, os programas modificam as condições em que os ribeirinhos formulam os seus projetos econômicos - seja de consumo ou de produção. A reação dos ribeirinhos a esse novo cenário socioambiental, por sua vez, muda o contexto em que operam tanto a Reserva quanto os benefícios, alterando dialeticamente as condições a partir das quais os moradores formulam a sua concepção de pobreza. No contexto de mudança em direção a uma condição pós-campesinato, em que a autonomia do consumo diminui, a questão da pobreza se torna paradoxal, como notamos anteriormente. $\mathrm{Na}$ medida em que crescem os rendimentos monetários e aumenta o envolvimento da produção e do consumo com o mercado, as familias passam a ser legitimamente classificáveis como pobres, e se tornam comparáveis a outros segmentos sociais para os quais a renda tem um significado central, mas não exclusivo, na definição de bem-estar e oportunidades.

\section{REFERÊNCIAS}

ADAMS, W.; HUTTON, J. People, Parks and Poverty: Political Ecology and Biodiversity Conservation. Conservation and Society, v. 5, n. 2, p. 147-183, 2007. ALMEIDA, M. Rubber tappers of the upper Juruá River, Acre: the making of a forest peasantry. Tese (Doutorado) - University of Cambridge, Cambridge, 1993.

BRONDÍZIO, E.; OSTROM, E.; YOUNG, O. Connectivity and the Governance of Multilevel Social-Ecological Systems: the role of social capital. Annual Review of Environment and Resources, v. 34, p. 253-278, 2009.

BUAINAIN, A.; DEDECCA, C.; NEDER, H. Características regionais da pobreza rural no Brasil: algumas implicações para políticas públicas. In: BUAINAIN, A.; DEDECCA, C. (Orgs.). A nova cara da pobreza rural: desenvolvimento e a questão regional. Brasília: Instituto Interamericano de Cooperação para a Agricultura, 2013. p. 57-110.

CARNEIRO DA CUNHA, M.; ALMEIDA, M. Populações tradicionais e conservação ambiental. In: CAPOBIANCO, J. P. (Org.). Biodiversidade na Amazônia brasileira: avaliação e ações prioritárias para a conservação, uso sustentável e repartição de benefícios. São Paulo: estação Liberdade; Instituto Socioambiental, 2001. p. 184-193. 
CASTRO, J.; MODESTO, L. (Orgs.) Bolsa família 2003-2010: avanços e desafios. 2 v. Brasília, DF: IPEA, 2010.

CHAYANOV, A. The Theory of Peasant Economy. Manchester: Manchester University Press, 1986.

CHIBNIK, M. A Cross-Cultural Examination of Chayanov's Theory. Current Anthropology, v. 25, n. 3, p. 335-340, 1984.

DOUGLAS, M.; ISHERWOOD, B. O mundo dos bens: para uma antropologia do consumo. Rio de Janeiro: EdUFRJ, 2004.

EGER, T.; DAMO, A. Money and morality in the Bolsa Familia. Vibrant Virtual Brazilian Anthropology, Brasília, v. 11, n. 1, 2014.

GOMES, M.; CORREA, D.; NASCIMENTO, A.; MOURA, E. Condições de uso da água em comunidades ribeirinhas das RDS Mamirauá e Amanã. In: SIMPÓSIO CONSERVAÇÃO E MANEJO PARTICIPATIVO NA AMAZÔNIA, 10, 2013, Tefé. Resumos... Tefé: Instituto Mamirauá, 2013.

IBGE-Instituto Brasileiro de Geografia e Estatística. Indicadores sociais municipais: uma análise dos resultados do universo do censo demográfico 2010. Rio de Janeiro: IBGE. 2011. (Série Estudos e Pesquisas, n. 28).

JUNK, W. J. General aspects of floodplain ecology with special reference to Amazonian floodplains. In: JUNK, W. (Ed.). The Central Amazon Floodplain: Ecological Studies, Berlin: Springer, 1997.

MCGRATH, D. The Paraense Traders: small-scale, long distance trade in the Brazilian Amazon. Tese (Doutorado) - University of Wisconsin, Madison, 1989.

MOTA, D.; SCHMITZ, H.; PORRO, N.; SILVA, J.; RODRIGUES, R. Interpretações de Programas de Políticas Públicas por mulheres extrativistas de Mangaba em Sergipe. Amazônica, Revista de Antropologia [Online], v. 5, n. 3, 2013.

NASCIMENTO, A. Censo Demográfico das Reservas Mamirauá e Amanã. Manuscrito em preparação, 2010.

PINEDO-VASQUEZ, M.; PADOCH, C.; SEARS, R.; BRONDÍZIO, E.; DEADMAN, P. Urbano e rural: famílias multi-instaladas, mobilidade e manejo de recursos de várzea na Amazônia. Novos Cadernos NAEA, Belém, v. 11, n. 2, p. 43-56, 2008. 
PIPERATA, B. A. The Nutrition Transition in Amazonia: rapid economic change and its impact on growth and development in Ribeirinhos. American Journal of Physical Anthropology, v. 133, n. 2, p.868-878, 2007.

ROCHA, S. Do consumo observado à linha de pobreza. Pesquisa e Planejamento Econômico, v. 27, n. 2, p. 313-352, 1997.

SANTOS, R. História econômica da Amazônia (1800-1920). Biblioteca básica de ciências sociais: Estudos brasileiros, v. 3. São Paulo: T.A. Queiroz, 1980.

SEN, A. Desenvolvimento como liberdade. São Paulo: Companhia das Letras, 2010 .

SNUC. Sistema Nacional de Unidades de Conservação da Natureza. Lei n. 9.985, de 18 de julho de 2000; decreto n. 4.340, de 22 de agosto de 2002. Brasília: MMA/SBF, 2002.

VERÍSSIMO, A.; ROLLA, A.; VEDOVETO, M.; FUTADA, S. de M. (Orgs). Áreas Protegidas na Amazônia brasileira: avanços e desafios. Belém: Imazon; São Paulo: Instituto Socioambiental, 2011.

VIANA, V. Bolsa Floresta: um instrumento inovador para a promoção da saúde em comunidades tradicionais na Amazônia. Estudos Avançados, São Paulo, v. 22, n. 64, 2008.

ZELIZER, V. Economic Lives, how culture shapes the economy. Princeton; Oxford: Princeton University Press, 2011. 
